Senad Rothkegel, Ljiljana Erakovic, Deborah Shepherd*

\title{
Strategic Alliances between SMEs and Large Firms: An Exploration of the Dynamic Process
}

This paper explores the dynamics in strategic alliances between small and medium sized enterprises (SMEs) and large organisations (corporates). Despite the volumes written on this subject, few studies take into account this context of interorganisational relationships. The dynamics in strategic partnerships between small and large organisations are potentially multifaceted and fraught with complexities and contradictions. The partner organisations bring diverse interests and resources to the strategic partnerships and these affect the dynamics of their relationships. Using the literature on strategic alliances, this article examines four such strategic partnerships in New Zealand. Results show that in order to increase the likelihood of successful collaboration, the alliance partners must understand the importance of building trust and a shared alliance purpose, and both of these must be communicated effectively at executive and operational levels.

Key words: Strategic Alliances, SMEs, Trust, Commitment, New Zealand

* Senad Rothkegel, Dr. Ljiljana Erakovic, Dr. Deborah Shepherd, The University of Auckland, The University of Auckland Business School, Department of Management and Employment Relations, Private Bag 92019 Auckland, New Zealand, phone: +64 9373 7599, fax: +64 9373 7477, e-mail: srot006@gmail.com, 1.erakovic@auckland.ac.nz, d.shepherd@auckland.ac.nz.

** The authors wish to thank two anonymous reviewers for critical comments and valuable insights.

Article received: November 15, 2005

Revised version accepted after double blind review: December 9, 2005. 


\section{Introduction}

Strategic alliances are assuming increasing prominence in the strategy of leading firms, large and small. They have become a means through which firms expand into new markets, access dispersed capabilities, and leverage technologies and other resources. In fact, some popular business writers argue that strategic alliances have become a necessity rather than a choice in today's turbulent business environment (Doz/Hamel 1998; Dussauge/Garrette 1999).

Despite the volumes written on this subject, very few studies take into account strategic alliances between small or medium-sized enterprises (SMEs) and large firms (Alvarez 2001; Farkas-Conn 1999; Sulej/Stewart/Keogh 2001). Most literature predominantly pertains to strategic alliances that are formed between large organisations (Hamel 1991; Kanter 1994). While such studies indeed provide relevant insight into the alliance phenomenon, it is important to note that many small countries including New Zealand are increasingly dependant on SMEs.

The research reported here considers the interplay in strategic alliances between SMEs and large organisations (corporates). By doing so, it hopes to provide better insight into what makes collaborative partnerships effective between SMEs and corporates. If indeed the effective use of strategic alliances is viewed increasingly as an important issue facing SMEs (Bekmann/Robinson 2004), what, then, is the importance of developing trust and commitment within strategic alliances, and how can an increased understanding of these and other relevant dimensions associated with effective collaborative partnerships be useful to other SMEs wishing to embark on similar strategies for growth?

The paper is structured as follows. The first three sections highlight some of the potential issues and challenges that might be relevant in the context of strategic alliances between SMEs and corporates. The fourth section outlines the research method while the fifth section offers insights into empirical investigation of four case studies of strategic partnerships. The final sections draw on the accumulated evidence presented in the previous sections to discuss three prominent aspects of strategic partnerships between SMEs and large firms, and identify potential areas for future research.

\section{The importance of strategic alliances}

The last two decades have witnessed a significant increase in the frequency and magnitude of strategic alliances. Despite their increasing popularity, both management scholars and practitioners (Das/Rahman 2001; Seligman 2001) agree that most strategic alliances have failed to fully accomplish their goals. Inkpen and Ross (2001), for example, describe strategic alliances as unstable organisational forms. Hutt and colleagues (Hutt/Stafford/Walker/Reingen 2000) note that many strategic alliances fail to meet expectations because little attention is given to nurturing the close working relationships and interpersonal connections that unite the partnering organisations. Formal contracts generally play a necessary part in establishing the conditions and performance milestones for collaboration. They may even provide the only basis on which business partners are prepared to work together in the first instance. Yet such contracts are rarely enough by themselves (Child 2001). Informal understanding, ba- 
based on dimensions such as trust and commitment, often prove to be more powerful factors in determining how the collaboration actually works.

Managing strategic alliances is therefore difficult. Organisations must select potential alliance partners wisely, which includes identifying partners with compatible goals and those willing and able to commit the needed resources (Ring/Van de Ven 1994). Once selected, alliance partners must reconcile the purposes of each organisation, at least in part, into a common purpose as well as develop compatible expectations for each other and for the strategic alliance (Doz 1996). Partners often have different goals not only for themselves, but also for the strategic alliance. Further, partners need to work with potentially different cultures, operating procedures, and governance structures (Borys/Jemison 1989). Such challenges are possibly more complex in strategic partnerships between SMEs and corporates due to the differences in size and power asymmetries.

\section{SMEs in the world of strategic alliances}

Definitions of SMEs differ across countries and industry sectors, and can be based on a variety of criteria, such as the number of employees, invested capital and total value of sales (Cameron/Massey 1999). Within the NZ context, this research will follow McGregor and Gomes' (1999) definition, who classify SMEs as entities with fewer than one hundred employees. Although, there is considerable discussion related to the appropriateness of categorising SMEs based on the number of employees (Jones/Tilley 2003), it is the most convenient and widely used categorisation. More important than the debate over SME definition is understanding better the challenges of growth for this sector of business.

The OECD (2000) provides elaborate commentary in this regard - "Many of the traditional problems facing SMEs - the availability of debt and equity financing, difficulty in exploiting technology where that is not the focus of the firm, constrained managerial capabilities, poor skill development and low productivity, regulatory burdens and international market access - become more acute in a globalised, technology-driven environment. This can hamper SME start-up, growth and competitiveness" (OECD 2000: 1).

The effects of globalisation and/or 'hypercompetition' (D'Aveni 1998) have intensified traditional barriers to growth for SMEs. Confronted with such challenges, SMEs have increasingly turned to strategic alliances to deal with these problems (Kishida 2002). Sulej et al. (2001), for example, observe that there has been an increasing use of strategic alliances as a mechanism for growth by SMEs, especially in innovative, technology-based industries. Strategic alliances between large companies and small firms in particular are increasingly common (Alvarez 2001; Slowinski/Seeling 1996). Alvarez (2001) illustrates that strategic alliances between biotechnology firms and pharmaceutical firms increased 341\% between 1993 and 1995. Similar growth rates can be found in the telecommunications, internet, electronics, and oil and gas industries (Alvarez 2001).

Although the potential benefits of strategic alliances with large firms are significant, they can easily be offset by the costs and risks of such alliances (Kishida 2002). Alvarez (2001), for example, reports that almost $80 \%$ of managers from small firms 
felt unfairly exploited by their large firm partners and that many firms went bankrupt. If indeed the effective use of strategic alliances is viewed increasingly as an important issue facing small, growth-oriented firms (Bekmann/Robinson 2004; Slowinski/Seeling 1996), understanding better what makes strategic alliances and/or collaborative partnerships effective within the SME sector is critical.

Although some literature has begun to address various issues associated with inter-organisational collaboration between SMEs and large firms (see for example Alvarez 2001; Farkas-Conn 1999; Hagedoorn/Narula 1996; Kishida 2002; Sulej et al. 2001), relatively little is known from this literature on how to successfully manage the relational aspects of collaboration between SMEs and corporates. Alvarez (2001) and Sulej et al. (2001), for example, predominantly investigate the potential pitfalls and risks involved in these kinds of partnerships. This paper attempts to explore this gap in literature by portraying the relationship dynamics of four New Zealand strategic alliances between SMEs and large firms.

\section{Managing strategic alliances: Issues and challenges}

Despite the increasing popularity of strategic alliances, many partnerships tend to fail and are terminated at excessively high rates. Das and Teng (2001) offer valuable insights into likely explanations for instability of strategic alliances. One of the pervasive problems faced by firms in strategic alliances is the potential for opportunistic behaviour (Das/Teng, 2001). In extreme situations, companies might join the alliance with the objective of using the partnership to exploit its partner company by, for example, trying to extract core competencies from the venture, or by using its influence over the investment and development process to reduce its partner's competitiveness (Barlett/Ghoshal, 2000). Such alliances, however, are presumably short-lived. Kishida (2002) suggests that small firms have a limited buffer against the negative outcomes of strategic alliances with large partners. Indeed, in some circumstances, strategic alliances with large firms can even threaten the very survival of a small firm (Alvarez 2001).

One way to negate the problem of opportunistic behaviour is to develop an adequate level of confidence in ones partner's cooperative behaviour (Ring/Van de Ven 1992). Das and Teng (1998) define confidence in partner cooperation as "a firm's perceived level of certainty that its partner firm will pursue mutually compatible interests in the alliance, rather than act opportunistically" (Das/Teng 1998: 491). Confidence arises from three distinct sources - trust, commitment and control (Das/Teng 1998; Whipple/Frankel 2000). All three dimensions are parallel concepts and their relationship is of a supplementary nature in generating confidence.

\subsection{The importance of trust}

Child (2001) suggests that trust is vital for any relationship - particularly when there is insufficient knowledge and understanding of the other party. His insights parallel those of Arrow (1972), who argues that "virtually every commercial transaction conducted has within itself an element of trust" (Arrow 1972: 357). In the context of interorganisational partnerships a certain minimum level of interfirm trust must exist (Das/Teng 1998). In fact, Volberda and Elfring (2001) argue that trust is a precondi- 
tion to success of alliances of all forms. A number of authors on the subject emphasise how trust promotes cooperation (Das/Teng 2001; Whipple/Frankel 2000), facilitates investment in relationship-specific assets (Dyer/Singh 1998; Hamel 1991), minimises transaction costs associated with the exchange (Volberda/Elfring 2001), accelerates negotiations (Reve 1990), and serves as an efficient governance mechanism (Ring/Van de Ven 1994). However, defining trust is not an easy task. Partly, one suspects, this is because of the numerous definitions that are put forward by various streams of academic traditions (Lewicki/Mcallister/Bies 1998). One common trait found in numerous fields, however, is the relationship between trust and vulnerability, as well as predictability and/or dependence (Volberda/Elfring 2001).

Some researchers conceptualise trust in multidimensional terms. For example, Whipple and Frankel (2000) examine trust from two distinct perspectives: characterbased trust and competence-based trust. Character-based trust deals with the qualitative characteristics of behaviour inherent in partners' strategic philosophies and cultures, while competence-based trust looks at specific operating behaviours and day-today performance (Whipple/Frankel 2000). Das and Teng (2001) clarify matters by suggesting that trust may concern a partner's ability to perform (competence-based trust), or their intentions to do so (character-based trust).

Several authors stress inseparability and vitality of trust and open communication if a strategic alliance is to succeed. Howarth and colleagues (Howarth/Gillin/Bailey 1995) argue that when trust is present, certain characteristics in a relationship can be identified. These include more open communication, the willingness to listen and confidence in the future success of the relationship (Howarth et al. 1995). This proposition is strengthened by the work of Hutt et al. (2000). The essence of their argument is that many strategic alliances fail to meet expectations because "little attention is given to nurturing the close working relationships and interpersonal connections that unite the partnering organisations" (Hutt et al. 2000: 42). However, human factors appear to have remained unconsidered or, at worst, dismissed in strategic alliance research (Hutt et al. 2000). A defining characteristic of trusting relationships, in this regard, are frequent interactions, the timely exchange of information, and accurate feedback on each partner's actions (Hutt et al. 2000).

Moore (1998) argues that the existence of trust in a relationship reduces the perception of risk associated with opportunistic behaviour and allows each party to believe that its goals will be fulfilled in the future. An extension of this argument, from a theoretical point of view, is that trust facilitates the creation of relation-specific investments (resource-based view) and stands as an effective governance mechanism by lowering transaction costs (Dyer/Singh 1998). They propose that trust facilitates the willingness of the alliance partners' to make relation-specific investments and combine resources in unique ways. In addition, Hutt et al. (2000) argue that informal psychological contracts, which are based on trusting personal relationships, by and large substitute for formal legal contracts.

\subsection{The importance of Commitment}

Besides trust, commitment has also been argued to be a key factor to strategic alliance success (Abodor 2002; Elmuti/Kathawala 2001; Spekman/Isabella/MacAvoy 2000). 
In general, commitment in a strategic alliance concerns a partner's intention to continue in a relationship (Cullen/Johnson/Sakano 2000). Spekman et al. (2000) note that commitment to an alliance signals both a sense of trust and a belief that the alliance has merit (i.e. creates value for both).

Commitment in strategic alliances can be examined from two distinct perspectives, as rational and attitudinal commitment (Cullen et al. 2000). The former focuses on tangible rewards from the strategic alliance, whereas the latter focuses on internalising the alliance relationship and making the extra effort to make the alliance work. Generally, rational commitment refers to the investment in relation specific, non-recoverable assets in the strategic alliance (Schreiner 2002). With attitudinal commitment, the strategic alliance assumes a position of status and importance because "there is a fairly deep psychological identification with the relationship and a pride of association with the partner and with the strategic alliance" (Cullen et al. 2000: 226).

However, Inkpen and Ross (2001) argue that too much senior management commitment (i.e. attitudinal commitment) may have its negative sides too. In particular, the more committed senior management becomes to a particular partnership, the more 'socially bound' they become and, thus, the more difficult it becomes to admit failure and withdraw from an alliance (Inkpen/Ross 2001). This is particularly true when senior management has invested not only a great deal of the firm's financial capital, but also a great deal of their 'personal political capital' (Inkpen/Ross 2001).

Nevertheless, management commitment is important not only to ensure the alliances receive the necessary resources, but also to convince others throughout the organisation of the importance of an alliance (Lorange/Ross/Bronn 1992). The latter is particularly relevant in the context of large firms forming partnerships with SMEs. "Everyone must be 'sold' on the concept relatively early on" (Lorange et al. 1992: 14). In many companies, however, strategic alliances are viewed as outside of the 'organizational mainstream' (Elmuti/Kathawala 2001). Therefore, organisational members may tend to view them as not as important as the company's core business. These 'internal' stakeholders, it is argued, may make or break the alliance. Thus, any company needs to ensure that their employees are committed to and enthusiastic about the strategic alliance. The task of senior management (Lorange et al. 1992) is to sufficiently explain the alliance idea and motivate others throughout the organisation.

\subsection{The importance of control}

Control can be defined as "a regulatory process by which the elements of a system are made more predictable through the establishment of standards in the pursuit of some desired objective or state" (Das/Teng 2001: 117). Beamish (1988) argues that firms in strategic alliances tend to be more confident about partner cooperation when they feel that they have an adequate level of control over their partners. From this perspective, formally established system of control will ensure (or, at least, raise the probability of) predictable behaviour among alliance partners (Spekman et al. 2000). However, Ohmae (1989) claims that "good partnerships, like good marriages, don't work on the basis of ownership and control ... [because]...you cannot own a successful partner anymore than you can own a husband or wife" (Ohmae 1989: 148). 
Insights from the works of Das and Teng (1998, 2001) might clarify matters in this regard. First, it is important to note that there are different types of control mechanisms. For example, the authors argue that alliance control can be achieved through governance mechanisms, contractual provisions, managerial arrangements, and some more informal means. Thus, "control in alliances is of two types: controlling the partner and controlling the alliance per se"(Das/Teng 2001: 258). Ohmae's marriage analogy, put into the context of informal mechanisms of control, is of value as proved by numerous empirical studies (see for example Das/Teng 1998, 2001; Kumar/Seth 1998).

According to Eisenhardt (1985) there are two basic approaches to control - external measure-based control and internal value-based control. Building on her work, Das and Teng $(1998,2001)$ discuss these two types of control in strategic alliances. They describe the former as 'formal control' and the latter as 'social control' (Das/Teng 1998). Formal control includes "outcome control and behaviour (or process) control, which measures, evaluates, and rewards either outcomes or behaviours" through the use of rules, standards and regulations (Das/Teng 1998: 500). In order to exert formal control, it seems, alliance partners require equity and/or contract-based form of control. The authors suggest that the use of formal control mechanisms undermine trust among partners. Surely, the excessive use of formal control mechanisms indicates a sense of distrust of the other party and may, therefore, not be conducive to the management of strategic alliances.

Social control, on the other hand, is about inducing desirable behaviour through 'soft' measures (Leifer/Mills 1996), such as creating shared values, beliefs, and goals. In the context of strategic alliances, two main mechanisms are identified by Das and Teng (2001) through which this can be achieved. First, partner firms can create shared vision and values through a participatory decision-making process (Grandori, 1997). Such a process ensures that the preference of each party is understood and integrated into mutually acceptable goals and plans. This is likely to reduce potential conflicts among the alliance partners and facilitate more cooperative working relationships. Second, partner firms can also stress cultural activities such as rituals and ceremonies to help create a culture of cooperation.

\section{Data and method}

The New Zealand economy is predominantly based around small and medium-sized businesses. The significance of SMEs in the New Zealand economy in terms of wealth creation and numbers employed is well documented. In 1999, SMEs accounted for 99.4\% of all companies in New Zealand, leaving fewer than 1500 enterprises in the large category. It is not surprising, then, that future economic prosperity for New Zealand depends on the survivability, performance and growth of the small and mediumsized enterprises sector (McGregor/Gomes 1999). According to the Ministry of Economic Development (2005), 96.3\% of enterprises in New Zealand employ 19 or fewer people and the majority of these $(86.8 \%)$ employ 5 or fewer people. Therefore, understanding better strategic alliances between SMEs and corporates is highly relevant to the NZ context but is equally important to other countries/economies similarly based around SMEs. 
This research was qualitative in its approach. Its main aim was to explore and gain better understanding of the dynamics of strategic partnerships between SMEs and corporates from the perception of key managers. Due to the lack of previous research, and the nature of the topic in general, exploratory case study method (Yin 1994) was adopted to investigate interfirm collaborations. Case study method has been previously employed in investigating the dynamics of alliance formation (see for example Beverland/Bretherton 2001; Eisenhardt 1989; Johnston et al. 1999; Parkhe 1993). In the context of this research, an attempt was made to gain the detailed knowledge about the organisations, processes underlying their behaviour and conditions under which the behaviour was expected to occur (Cassell/Symon 2004).

\subsection{Data collection and data analysis}

Potential participants were identified through a business incubator, a collaborative partnership between the largest New Zealand university and several New Zealand's leading corporations. The incubator's wide and established network of contacts in the SME community was exploited to identify potential participants. Eight organisations, four SMEs and four large corporates, partners in current collaborative arrangements agreed to participate in the study. An attempt was made to interview a senior level manager of each partnering organisation. Table 1 shows the different types of informants and case studies. Due to the sensitive nature of the information, we decided to keep the anonymity of all participants and their respective companies. Accordingly, all companies were given pseudonym names.

Table 1: Participants and participating companies

\begin{tabular}{|l|l|l|l|}
\hline & Firm Type & Pseudonym Name & Informant's Role \\
\hline Partnership One & SME & TeleDynamics & Managing Director \\
\cline { 2 - 4 } & Large & Telco & Partner Account Manager \\
\hline Partnership Two & SME & Exxel & CEO \\
\cline { 2 - 4 } & Large & I Tech & $\begin{array}{l}\text { Head of Innovation \& New Ven- } \\
\text { tures }\end{array}$ \\
\hline Partnership Three & SME & Milky Way & Managing Director \\
\cline { 2 - 4 } & Large & Dairy Inc & Operations Director \\
\hline Partnership Four & SME & Pulp Fiction & Managing Director \\
\cline { 2 - 4 } & Large & Alpine Forest & Wood Resources Manager \\
\hline
\end{tabular}

All interviewees were asked a series of open-ended questions about their partnership experience. In addition to the interviews, we collected data from numerous secondary sources, such as industry publications, company brochures and websites, as well as newspaper articles. Such sources are frequently utilised as a means of gaining access to publicly available information that may give the researcher indications about the topics of interest for the study (Hall/Hall 1996). In the context of this research, secondary sources of data were helpful in gaining knowledge about the each company's history and preparing for the interviews.

Data analysis was performed at two levels: within-case and across cases. For the within-case analysis, each case was treated as a comprehensive case in and of itself 
(Merriam 1988). Within-case analysis involved the coding of interview transcripts and development of emerging themes. The overall objective of the within-case analyses was to become familiar with each case as a stand-alone entity and provide a 'snapshot' of the dynamics inherent in managing a strategic alliance between an SME and a large firm. This process produced a detailed description and enabled an in-depth understanding of the conditions and relationships in each case before we moved towards finding patterns across cases (Eisenhardt, 1989).

Following analysis of each case, the next task involved the searching for crosscase patterns of the data by locating and examining similarities and differences across them. The overall idea behind cross-case analysis is to force the researcher to go beyond single cases to uncover emerging issues (Eisenhardt, 1989).

\section{Empirical findings}

Each partnership is presented in case study mode, offering a brief overview of the businesses, the purpose of the partnership, and the major findings. The findings reveal several recurring themes that emerged from the cases which are explored more fully in the discussion section.

\subsection{Partnership One}

In this particular partnership, TeleDynamics, the small company implements and supports the Customer Relationship Management (CRM) software for the large company, Telco. TeleDynamics does not have an exclusive partnership with Telco, and Telco has at least eight other partners that perform the same activity in New Zealand.

TeleDynamics has been in the business of customer contact implementation and contact centre optimization for the past ten years. The company implemented 'Contact centre solutions' for leading banks, insurance companies, telecommunications companies and utilities throughout New Zealand, Australia and Asia. Currently TeleDynamics employs 18 staff.

From its inception at this market, Telco has adopted a partner-driven business model. In order to formally accommodate different kinds of partners, Telco has developed a multi-level partner program. The goal of the program is to bring together those partners who complement Telco's technical and marketing innovation, enabling them at the same time to capitalize on new opportunities and bring Telco's products and services closer to customers.

Within the context of Telco's partner program, TeleDynamics is a Certified Partner. In order to become a Certified Partner TeleDynamics has had to meet a number of requirements, such as paying the Telco Partner Program annual membership fee and employing or contracting at least two exclusive Telco Certified Professionals. This partnership is relatively 'formal but distanced' meaning that it is based on an online application procedure, where one can, according to TeleDynamics' Managing Director, "enter into a partnership with Telco without ever seeing anyone".

This partnership reveals interesting insights in the context of managing a formal strategic alliance between an SME and large organisation. This partnership is not one based on a close relationship and commitment from the corporate partner. While TeleDynamics was keen to engage in a deeper level of cooperation with its partner re- 
quiring more personal interaction, Telco's management revealed that they did not see all of their partnerships as important simply because they had so many. Telco management acknowledged that they had "partners that are not really partners". For TeleDynamics as a small partner, such a stance poses significant challenges and risks. The managing director noted:

[We] are investing time, effort, and money into becoming familiar with Telco's products on the understanding that there is a market. We are a Certified Partner but that doesn't mean anything. I wanted to let them know who we were and what we were capable of doing. That is not a requirement of the partnership but we felt that we needed to try to improve our relationship. .... However, it's hard to get support and identify people at Telco. Cooperating with Telco creates a dependency for TeleDynamics and increases its company's vulnerability to the possible actions of Telco. Although both companies were referring to their relationship as "commonality of purpose", TeleDynamics appeared to have a somewhat different view on the durability of the partnership. In particular, TeleDynamics referred to the relationship timeframe as being there for the 'long haul' by referring to their partnership with Telco as 'the way to go'. In contrast, Telco's manager stressed the replaceability of their numerous partners, by stating that Telco can easily change partners if they "no longer are meeting their objectives" or "Telco's objectives have changed".

The most striking aspect of this case is the lack of commitment on the side of the corporate partner and an emphasis on building commitment, trust and long-term relationships on the side of the SME. Contrary to Telco, which perceives this and similar partnerships as just useful collaborative arrangement to gain better access to the local customers, TeleDynamics considers Telco's approach as a critical obstacle in developing a 'real partnership' as it aims for a more committed, personalised and stronger relationship with its partner.

\subsection{Partnership Two}

Exxel, 'a business accelerator', is a not-for-profit organisation focusing on business growth for the SME sector. It offers a range of growth interventions for the SME sector, including incubation and education programmes. The incubator accommodates up to 15 companies, giving them access to international networks, consulting advice and capital providers while the education arm offers growth programmes for owner managers. The structure of Exxel is a partnership between a number of large corporates including a bank, telecommunications company, law firm, software company, IT company, university and two consulting companies. Initially, all eight partners contributed NZ\$2.5 million into this partnership in order to grow and develop entrepreneurial endeavours from their early stages into substantial international businesses.

One of the partners in Exxel is a New Zealand subsidiary of a large MNC in information technology industry (I Tech). The primary motivation behind I Tech's entrance into this partnership was the company's desire to "create a forward path and support over time for SMEs". By doing so, I Tech was hoping to "build a market" for their products by gaining visibility in the SME sector.

While it is true that both, the large IT company and SMEs who participate in the Exxel business growth program, share a common purpose, their respective time hori- 
zon, in which they expect to benefit from this partnership is somewhat different. Exxel's incubation program generally last between 18-24 months, during which incubator residents (i.e., early stage SMEs) gain access to the I Tech's international networks, consulting advice, and computing, printing, and digital imaging hardware. Essentially, SMEs have a relatively short-time horizon in that they are primarily interested in the period, during which they participate in the incubation program. I Tech's partnering objective, however, is more long-term as the company is trying to "build a market". I Tech recognises the "future value of SMEs" and, as such, is trying to establish and promote a favourable relationship with the SME sector.

Such differences are interesting in the context of the discussion on managing competing stakeholder expectations and what one I Tech manager described as the "level of exclusivity". Exxel's CEO noted in this regard that "working with one partner often excludes working with others within the partners industry". He also described instances where Exxel have had issues around expectations:

"We had an idea of what we expected from a partner. And the partner was less interested or not interested in pursuing that particular avenue. It's about a misunderstanding of differences in objectives. We have addressed these issues by adjusting the expectations on one or both sides and by redefining the nature of our relationship."

In terms of partners' 'realistic' objectives and expectations, I Tech's manager emphasised the ability of both parties to understand the differences in the dynamics of corporate partners and SMEs. SMEs need to acknowledge that corporates are, generally, not as flexible. Very often larger firms may find it difficult to keep time schedules. "You can assume that we will follow up on their commitments" but "we are not as agile".

Open and honest communication between partners has been seen as a common way to overcome the problems of unrealistic expectations. Exxel's CEO, for example, acknowledged the importance of having many points of contacts on both sides: "Exxel has multiple people contacting multiple people within each of the eight partners". He also emphasised the importance of both formal and informal communication. Regular meetings, formal monthly reviews, informal social activities or the CEO interacting with the partners on an ad hoc basis, have all been described as mechanisms for effective communication.

Although both partners regarded trust as an essential consideration for effective management of their partnership, they clearly pointed out that close personal relationships are not necessarily essential to effective collaborations. Excell's manager stressed that there are different partner relationships. In some instance there is no interest by one party or by both parties in having informal, social relations. However, both partners emphasised the importance of the partnership as a 'win-win situation'. Exxel's manager emphasised that an effective partnership is one where all parties "benefit in the relationship". A similar insight emerged from the discussion with the I Tech's manager, who pointed out how most firms (small or large) have not developed a culture of partnering. Although companies say that they are partner focused, they do not develop their partnership by making sure that the partner wins more often than they lose. 
This partnership highlights the importance of partners sharing the understanding of the purpose of their collaborative arrangements and understanding the differences in business horizons and dynamics of small and large organisations. Although the value of the development of personal ties is less emphasised, managers from both companies recognise the importance of open and honest communication between partners as a means towards more effective management of each others' expectations.

\subsection{Partnership Three}

The strategic partnership between Milky Way (SME) and Dairy Inc (corporate) was formed seven years ago when Milky Way negotiated with dairy giant Dairy Inc to manufacture and distribute Milky Trim in the Auckland region. Milky Way is a functional food company focused on delivering milk based products to the market. Dairy Inc is a leader in the New Zealand dairy industry, with a strong domestic and growing international business. Central to Dairy Inc's success is its brand portfolio, which contains some of the most recognised consumer brands in the country. By accessing wellestablished manufacturing capabilities and distribution channels, Milky Way has established itself as a niche player in the functional foods market in New Zealand. Dairy Inc, on the other hand, has benefited from this partnership in that they receive a share of the profit from the sales on the niche market.

While the rationale for the partnership is apparent, interestingly, both partners expressed dissatisfaction with the current relationships. Firstly, the partnership was built on somewhat rocky foundations. For five years, the two companies were major competitors. Milky Way's Managing Director explained their rivalry in this way: "Dairy Inc has never welcomed us. They don't like competition. So we have been in the market place with what we belief to be a premium product and they have been competing to stop us. But eventually as they never killed us off they decided to do something with us." The antecedent conditions of their relationships have important effects on the current dynamics in this partnership. Given the unequal balance of power between Dairy Inc and Milky Way, the circumstances in which this particular strategic alliance was formed may not be conducive for a positive working relationship. Secondly, the partners' unwillingness to understand operational issues of each other business induced various problems for both. For instance, differences between the large organisation, where cash flow is not a problem, and SME, where managing cash flow is crucial to month-to-month survival are specifically stressed by Milky Way. Dairy Inc's manager, on the other hand, acknowledged the issues with quality and reliability in relationships with the smaller partner. Thirdly, the companies' impressions on the value of the partnership for each other significantly differ. Whereas Milky Way's Managing Director believes that Dairy Inc's CEO and other senior executives accepts this partnership as hugely beneficial to their own company, the Operations Manager at Dairy Inc is not aware of the beneficial nature of the relationship with Milky Way. In fact, he has considerable doubts whether Dairy Inc would enter into this kind of an alliance with a smaller partner ever again. When asked, he could not clearly articulate what value Milky Way brings to his organisation.

Both partners, however, agree on the importance of trust in collaborative arrangements. Dairy Inc's Operations Manager, for example, pointed out that "personal 
relationships are the key to business success". A similar insight emerges from Milky Way's Managing Director who pointed out that "partnerships are all about personalities". For them to work "there has to be two personalities coming and enjoying each other". Even though the Managing Director at Milky Way was quite enthusiastic about his working relationship with Dairy Inc's CEO on a strategic level, he was less fervent about his relations with Dairy Inc's operational staff. For example, he pointed out the problems related to significant staff turnover of operational managers in Dairy Inc. From his point of view, it is certainly understandable that "it's hard to build good personal relationships if personalities keep changing". The impression is that new staff at Dairy Inc might not be able to see the rationale for partnering with Milky Way".

This partnership captures the multifaceted complexity of relationships between SMEs and corporates. In addition to the unclear purpose of this collaborative arrangement for both partners, which has contributed to a deviation of the partners' commitment, we can also highlight a lack of understanding of each others' business dynamics and lack of competence-based trust. The case also indicates how the significant staff turnover and inadequate communication in one of the partner organisations may become a key inhibitor to the effective partnership.

\subsection{Partnership Four}

This collaborative arrangement can be described as a vertical partnership between Pulp Fiction (SME) and Alpine Forest (corporate). Pulp Fiction is a small timber company that manufactures and distributes processed lumber and lumber products, primarily for export to Asian markets. It employs approximately 24 people. From its inception in 1971, Alpine Forest's main purpose was to provide wood fibre for its shareholders' paper making operations in Japan. In New Zealand, Alpine Forest is the sole supplier of the unique kind of 'Radiata pine'.The rationale behind this strategic alliance from Pulp Fiction's perspective is simple: securing a steady supply of 'Radiata pine'.

The key distinguishing feature of this partnership case is that both companies viewed their operations with a great deal of uncertainty. The industry's cyclical nature, which is highly dependent on exchange rate fluctuations and the price of oil, means that both companies regard their partnership as a 'rock of stability in the sea of change and challenge'. It is not surprising, then, to find that trust and close personal relationships play an essential part of this collaboration. The Alpine Forest manager interviewed emphasised a dependence of his company on their smaller partner as an exclusive buyer and significant source of revenue. Each delivery of Radiata pine was worth over half a million NZ dollars. Pulp Fiction's manager, on the other hand, stressed the importance of keeping steady financial relationships from their side as the condition for the future continuous supply.

Both partners considered this partnership as valuable on the long-term. They were both ready to promote each other's interests and provide some leverage to each other in difficult times. To this end, the larger partner Alpine Forest, in spite of the significant size asymmetries, treated its smaller counterpart as an equal partner. The large partner was neither a dictator nor a silent partner, but rather an active participant in the partnership. Pulp Fiction's Managing Director, although acknowledging the 
risks, was adamant about his trust in Alpine Forest and the long-term nature of this strategic partnership: "This is a long-term partnership and we'll see how it unfolds over time. I fully trust Alpine Forest." The manager at Alpine Forest stressed how this long-term philosophy is a part of the company's cultural predisposition. In particular, he attributed it to the Japanese ownership of the company and Japanese principles of developing business. He also noted that although "there are no significant economic benefits to this relationship at the moment, they are likely to be significant in the medium to long-term".

Such long-term view in building collaborative arrangements with small players from the industry helped senior mangers at Alpine Forest to explain the purpose and benefits of this partnership to staff internally. This was seen as an essential consideration for avoiding misunderstandings and managing a strategic alliance successfully. In a large company such as Alpine Forest, with over 300 employees, it is easy to forget where the partnership is situated within the value chain. Therefore, the senior management role was to disseminate information about the partnership and convince people at the operational level to become committed and trustful to such an arrangement. This was particularly important as the benefits were perceived to occur only in the long-term.

Again, this case illustrates the importance of trust and shared temporal frameworks among partners for effective strategic partnerships. Partners illustrate trust both in the context of the partner's ability to effectively fulfil its contractual obligations and in the context of managers' reputation, honesty and integrity. This partnership also demonstrates the willingness of both organisations to communicate and understand their individual motives. Their mutual efforts and the partnership rationale should be perceived within a high level of environmental uncertainty for both partners.

\section{Discussion}

The four cases from this research demonstrate that the dynamics in strategic partnership between SMEs and large corporates are potentially multifaceted and fraught with complexities and contradictions inherent to this asymmetric relationship. Within-case analyses indicate that the development of each partnership is unique and that each has found ways of working effectively together albeit in quite differing styles. Each partner brings diverse interests and resources to the strategic partnerships, affecting the dynamics of the various relationships along a number of dimensions. The research proposition, driven from the literature on strategic alliances and from our four cases, suggests that the effective strategic collaborations between SMEs and corporates are reflection of three elements: trust, understanding of purpose, and personal ties. In our discussion we mainly reflect on the framework offered by Das and Teng $(1998,2001)$ by pointing out how the above elements interrelate in the alliances between asymmetric partners.

\subsection{Trust in asymmetrical strategic alliances}

Successful alliances exhibit trust between the partners; unsuccessful alliances exhibit a lack of trust. No other statement about alliances would produce the universal agreement than this assertion would receive (Koza/Lewin 1998: 258). This supposition is 
generally well supported across all four case studies. While all interview participants discussed and recognised the importance of trust in their partnerships, there were interesting differences in both the conceptualisation and operationalisation of this variable. Some participants discussed trust as a context specific construct; others kept the discussion more general without specifically referring to their strategic alliance partner. However, this study revealed that in certain types of alliances, trust is not an essential precondition. While a certain minimum level of trust is recognised in every alliance (Das/Teng 1998), in certain strategic partnerships trust may not be a necessary requirement in order to collaborate effectively - at least in the shorter term or where the parties did not invest in non-recoverable specific assets (Williamson 1991) or even where there was no dependency (Douma/Bilderbeek/Idenburg/Looise 2000). Two of the cases, Partnership One (Teledynamics/Telco) and Partnership Three (Milky Way/Dairy Inc), prove this point. TeleDynamics entered into a partnership with Telco in the absence of any kind of character-based trust, whereas operations manager at Dairy Inc explicitly emphasised that he did not trust his alliance partner yet they have found a way to work together sufficiently enough in order to achieve their individual goals. What is not clear though is how sustainable such strategic relationships are over a longer time-frame. If character trust is not present then one might assume that commitment is at best ambivalent and at worst marginal over time.

This research also highlights that trust means different things to different people. In the context of this study, most interviewees conceptualised trust in multidimensional terms. Telco's manager, for example, distinguished between organisational trust and individual trust. Essentially, he was referring to competence-based and characterbased trust. Other interviewees too discussed trust from these two perspectives. Such conceptualisations are consistent with that of Das and Teng (2001). These two trust dimensions might be usefully understood from a levels perspective whereby competence-based trust resonates as organisational level construct while character-based trust is more likely to sit at the individual level. Having a strategic partnership based predominantly on character-trust (as in both the Exxel/I Tech and Pulp Fiction/Alpine Forest cases to some extent) leaves the partnership vulnerable to personnel changes. Ideally, shifting the character-trust to include competence trust also makes the SME less exposed to changes within the corporate landscape.

Some of the participants also emphasised the importance of building trust in order to create a more conducive atmosphere of collaboration, while others linked trust to things such as commitment and/or risk. In the context of SME-corporate partnerships, building trust has an additional dimension. The managers of the large-firms emphasised the importance of establishing competence-based trust, or the ability to effectively perform the alliance expectations, simply because there was little risk involved in terms of collaborating with their small counterparts. Das and Teng's (2001) empirical work on the relationship between competence-based trust and performance risk may contextualize matters. From a large firm perspective, Das and Teng's (2001) insights suggest that competence trust gives the large firm a sense of confidence that the small partner is capable of accomplishing given tasks in the alliance. Yet gaining access and opportunities to corporates for many SME managers centres around being able to first build character trust in order to get a 'foot in the door'. Contrary to their 
large counterparts, the SMEs' managers in our four cases emphasise the importance of character-based trust (Whipple/Frankel 2000), as they risk significantly more both in terms of relational and performance risk. In order to better achieve the alliance objectives, the SME managers were looking for open and prompt communication with their large partners (e.g. TeleDynamics), asking for better understanding of the operational problems/challenges (Milk Way) and working toward building long-term relationships (Pulp Fiction). For SMEs, the lack of character-based trust, resulted in high levels of relational risk (real or perceived), corroborating the findings of Das and Teng (2001).

\subsection{Understanding the mutual interest in asymmetrical strategic alliances}

Extant literature suggests that alliance success requires the establishment and execution of clearly defined goals (Douma et al. 2000; Elmuti/Kathawala 2001; Spekman et al. 2000). Such commentary is well supported across three of the four case studies such that these partnerships were based on a mutually beneficial purpose. Key personnel from each partner organisation appeared to meet regularly and review the agreements against the objectives. There was, however, an intriguing contradiction in the case of Milky Way and Dairy Inc in terms of the understanding and/or valuing of what each party brought to the partnership and how this partnership contributed to each individual organisation's strategic goals. Hutt et al. (2000), among others, postulate that beyond establishing joint goals and determining how the alliance fits each firm's total strategy, senior executives define the meaning of the relationship and signal its importance to personnel in the respective firms. In this instance, executive leadership also assumes a critical role in communicating the strategic role of the strategic alliance and in creating an identity for the alliance within the organisation (Hutt et al. 2000). These behaviours were distinctly missing in the relationship between Milky Way and Dairy Inc and it appeared that the partnership stayed together, despite feelings of distrust and in spite of differential reasons for the partnership, because both organisations stood to gain more from working within a difficult relation than working alone (and therefore by default in competition with each other).

Managers from two of the other corporate partners, I Tech and Alpine Forest, both strongly emphasised the importance of articulating the purpose and the benefits of the strategic alliances within their respective organisations. This was seen as an essential consideration for managing a strategic alliance successfully. The manager at Alpine Forest, for example, acknowledged that for his large and diversified organisation it could be easy to ignore potential benefits of the partnership with a small company such as Pulp Fiction. The role of senior management therefore becomes ever more important to disseminate information about the alliance to the organisation as a whole.

By contrast, the manager at Dairy Inc does not acknowledge his role in communicating the importance of the strategic alliance within his organisation. However, he pointed out an important element for large organisations in such partnerships - a degree of dependence. Such observation is consistent with Douma et al. (2000) concept of 'fit' which is very much related to the requirement for complementary balance, mutual benefits, and dependence. 
Regarding the 'fit' (Douma et al. 2000), our cases in general do not exemplify mutual dependence. If the strategic alliances between Milky Way and Dairy Inc and Pulp Fiction and Alpine Forest are compared, a solid case can be made for the relationship between alliance success and dependency. For example, Pulp Fiction and Alpine Forest were equally vulnerable to the possible actions of their counterparts. Dairy Inc, however, was not mutually dependent on Milky Way. This may then account for why both companies in the Milky Way/Dairy Inc partnership expressed dissatisfaction with the current partnership. Research shows that, generally, smaller firms are placed in highly vulnerable positions when attempting to collaborate with their larger counterpart (Sulej et al. 2001). Levinthal (1991), for example, suggests that the cumulative resources of large firms may absorb small mistakes and losses over short-term, whereas start-ups can be very vulnerable to one or few wrong choices.

Given the vast size and resource asymmetries, it seems that most large firms from our research do not play an equal part with their small counterparts in their joint partnerships. In most circumstances it is very difficult for SMEs to create a mutual dependency. Telco's accentuation of the interchangeability of their partners best illustrates this point. In its partnership with TeleDynamics, the key point revolved around the issue of managing different kind of partners. Can we partner with someone else and achieve more? Is this partnership still productive? Should we spend more time with other partners? Questions such as these surfaced the large company's major concerns and illustrated the absence of mutual dependence within its small partners. For TeleDynamics on the other hand, the relationship with Telco was absolutely critical to its business survival let alone success. Therefore one of the challenges for SMEs in strategic alliances is removing as much as possible one-way dependence that leaves their business model overly exposed to the actions of a single large client. Ensuring there is a mutual interest to the alliance, albeit that this interest may align with each partner organisations' goals differently is critical to successful asymmetrical strategic alliances. Shared purpose is a necessary component in ensuring shared commitment to the success of the alliance over time and reducing the risk profile for both partners, but particularly the SME partner.

\subsection{Personal ties in asymmetrical strategic alliances}

Findings from this research demonstrate that the development of personal ties is an essential condition for partnering effectively. These findings are supported by many previous studies (see for example Beekman/Robinson 2004; Eisenhardt/Schoonhoven 1996; Kanter 1994; Rodriguez/Wilson 2002) which highlight the criticality of personal relationships in the alliance process. In this research, small partners in particular emphasised the importance of personal ties with the owner managers of these SMEs suggesting that more personal interaction from both partner companies is needed if a deeper level of cooperation is to be achieved. We argue that partners, small and large, need to go beyond the obligatory requirements to secure a closer personal relationship in order to achieve the partnership objectives. There is little possibility that meaningful cooperation can be developed from formally negotiated arrangements only which are typically linked to economic or strategic exchanges, if these are not supported by personal relationships (Rodriguez/Wilson 2002). 
Development and maintenance of sound personal relationships at the upper managerial echelon was emphasised across the four case illustrations. These were considered key to business success. Partners' executives needed to meet regularly and discuss issues and opportunities. Such practices are congruent with Kanter's (1994) argument that "successful company relationships nearly always depend on the creation and maintenance of a comfortable personal relationship between senior executives" (Kanter 1994: 98). She also postulates that the rapport that is initially developed between the chief executives of the involved firms must be approved and broadened to include other significant members of the firm. Two of the current research cases illustrate these points. The lack of communication between executive and operational managers at Milky Way and Dairy Inc potentially limits the long term possibilities of this partnership quite considerably while the readiness to communicate the long term purpose of partnership with the whole organisation at Alpine Forrest significantly enhances the working relationship between the companies of Alpine Forrest and Pulp Fiction not just the relationship between two individual managers. The former approach has consequently contributed to lack of trust and enthusiasm for the joint endeavour, whereas the latter approach has proved useful even (or perhaps more so) in the situation where the short term economic benefits are not clear. Lorange et al. (1992) postulate, in this regard, that management commitment is not only important to ensure the strategic alliance receives the necessary resources, but also to convince others throughout the organisation of the importance of an alliance. This is where character-based trust (between individuals) needs to be broadened to competencebased trust (between organisations) to reduce the extent to which the SME in particular may be exposed. Here, the partnering organisations need to ensure that all internal stakeholders 'buy into' are committed to, and ideally even enthusiastic about, the strategic alliance (Lorange et al. 1992). Das and Teng (2001) also emphasise how the correlation between individual- and organisational-level trust is instrumental in developing effective strategic alliances.

As mentioned, another important condition in developing personal ties across the organisation at various touch points and hierarchical/positional roles in collaborative arrangements is related to staff turnover. If indeed a successful partnership requires strong personal relationships, the high staff turnover in any of the partner might be a real issue. Spekman et al. (1996) discuss the importance of building interpersonal ties among alliance staff by quoting a manager:

It takes a lot of time - in some instances 3, 4, 5 years to understand the other side. If people move too quickly, somebody is coming up and they move them out, this happens a lot... that causes problems because a good partnership means continuity in the people who are involved - not changing too often. (Spekman et al. 1996: 351)

This continuity was certainly not present in the strategic alliance between Dairy Inc and Milky Way. Significant levels of departure by senior staff from the large partner organisation have contributed to the lack of development of good and commercially successful inter-organisational relationships.

On the other hand, the partnership between I Tech and Exxel illustrates efforts in building close relationships between all partners. In particular, Exxel encouraged the development of personal relationships by organising social activities with their 
partners (e.g. 'First Friday Drinks' evenings). Essentially, the idea is to provide an opportunity for the managers involved to get to know each other better and form personal bonds. Such rituals are designed to encourage the development of attitudinal commitment. In this instance, Das and Teng (2001) have advocated the importance of informal ways (for example, rituals, ceremonies and networking) of influencing individual behaviour and increasing their commitment to the goals of the strategic alliance. If the alliance partners go beyond mere contractual obligations and develop an attitudinal commitment to the relationship, it is argued, then the relationship can often sustain periods of unequal exchange (Cullen et al. 2000).

This discussion has identified numerous recurring themes across all four case studies investigated. These are the importance of trust, the importance of understanding mutual interests and the importance of personal ties in asymmetrical strategic alliances. These dimensions are critical in developing commitment to the partnership objectives, particularly over a longer time horizon. We have found that our findings coincide with the literature on strategic alliances. In addition, the findings have indicated that the dynamics in strategic partnerships between SMEs and corporates are multifaceted and fraught with complexities and contradictions inherent in this asymmetric relationship.

\section{Conclusion}

The main objective of this study was to explore the dynamics in strategic alliances between SMEs and corporates. Despite the volumes written on this subject, few studies take into account this context of inter-organisational relationships. This research study set out to explore this gap in literature by considering the dynamics of such asymmetrical strategic alliances. As more and more SMEs world-wide look to partner large corporates as a strategic initiative it is critical we better understand what this means for both parties in the asymmetrical relationship but particularly the SME which is typically more vulnerable and exposed in such alliances.

We found that SMEs can be, and are, successfully partnering large firms. In order to increase the likelihood of success for all parties, large and small, alliance partners must open the 'black box' pertaining to each particular strategic alliance. This means that alliance partners must recognise the uniqueness of each case. They should have a clear understanding of the complexities and contradictions at the individual as well as the organisational level. Careful consideration of each element is critical for partnership success.

On an individual level, strategic partnerships between SMEs and corporates require the establishment and maintenance of character-based trust. Respect and interaction of people between organisations are the necessary conditions. Here, the establishment of personal ties at the management level is advocated. Once established, close personal ties have been found to increase character-based trust and reduce relational risk (i.e. the fear of the partner not cooperating in good faith). In addition, this research study suggests that close personal ties may be linked to alliance durability.

On an organisational level, strategic alliances between SMEs and large organisations require systems and structures that facilitate collaboration. For starters, strategic partnerships between SMEs and corporates require the establishment and execution 
of clearly defined goals and performance measures. To achieve these goals, welldefined procedures must be clearly communicated to the managers involved with the alliance. Furthermore, the alliance partners must have systems in place that facilitate the dissemination of information about the alliance throughout the staff of both partners. Without these, partnering organisations will not be able to understand the purpose of the alliance, nor will they acknowledge the completely differential operating realities of their counterparts. In addition, large firms, above all, emphasise the importance of competence-based trust, which is based on a partner's perception of the others competence to fulfil their particular role or task.

\section{Implications for future research}

There are several areas of future research emerged from this study. First, it has already been noted that there is little, if any, literature on the consequences of high staff turnover in the context of managing strategic alliances. Given its significant implications to the dynamics in strategic alliances between SMEs and corporates, more research is required to fully understand this phenomenon and its implications thereof.

The second area of future research is the role of trust in asymmetrical relationships of strategic partnerships. Although research on trust in strategic alliances is thorough (see for example Das/Teng 1998; Child 2001; Spekman et al. 1996), more investigation is required to fully understand the complexities in strategic alliances between SMEs and large firms. For example, Alvarez's (2001) study of strategic alliances between entrepreneurial firms and large organisations has touched briefly on the importance of building trust. However, more insight is needed into the multidimensional nature of trust and how different types of trust interact to affect the dynamics in strategic alliances between SMEs and corporates.

A third area of future research is to examine the interrelationship between the key elements of strategic partnerships, like trust, personal ties and risk. Das and Teng (1998), for example, have already investigated two interrelated concepts - trust and control. In their later work, the authors (Das/Teng 2001) have incorporated the concept of risk to the trust-control relationship. Similar research could be done to shed some light on the interrelationship of trust, personal ties and risk in the context of strategic alliance between SMEs and large firms.

\section{References}

Alvarez, A. S. (2001) : How entrepreneurial firms can benefit from alliances with larger partners. In: Academy of Management Executive, 15 (1): 139-148.

Arrow, K. (1972) : Gift and exchanges. In: Philosophy and Public Affairs, 1 (4): 343-362.

Barber, J. / Metcalfe, J. S. / Porteous, M. (1989) : Barriers to growth in small firms. London: Routledge.

Barlett, C. A. / Ghoshal, S. (2000) : Transnational management: Text, cases, and readings in cross-border management ( $3^{\text {rd }}$ edition). Boston: McGraw-Hill Higher Education.

Beamish, P. (1988) : Multinational joint ventures in developing countries. London: Routledge.

Bekmann, A. / Robinson, R. (2004) : Supplier partnerships and the small, high-growth firm: Selecting for success. In: Journal of Small Business Management, 42 (2): 59-77.

Beverland, M. / Bretherton, P. (2001) : The uncertain search for opportunities: Determinants of strategic alliances. In: Qualitative Market Research, 2 (4): 88-99.

Borys, B. / Jemison, D. B. (1989) : Hybrid arrangements as strategic alliances: Theoretical issues in organizational combinations. In: Academy of Management Review, 14 (2): 234-249. 
Cameron, A. / Massey, C. (1999) : Small and medium-sized enterprises: A New Zealand perspective. New Zealand: Longman.

Child, J. (2001) : Trust - The fundamental bond in global collaboration. In: Organizational Dynamics, 29 (4): 274-288.

Cullen, B. J. / Johnson, L. J. / Sakano, T. (2000) : Success through commitment and trust: The soft side of strategic alliance management. In: Journal of World Business, 35 (3): 223-240.

Das, T. K. / Teng, B. (1998) : Between trust and control: Developing confidence in partner cooperation in alliances. In: Academy of Management Review, 23 (3): 491-512.

Das, T. K. / Teng, B. (2001) : Trust, control, and risk in strategic alliances: An integrated framework. In: Organization Studies, 22 (2): 251-283.

Das, T. K. / Rahman, N. (2001) : Partner misbehaviour in strategic alliances: Guidelines for effective deterrence. In: Journal of General Management, 27 (1): 43-70.

Davidsson, P. (1991) : Continued Entrepreneurship: Ability, need, and opportunity as determinants of small firm growth. In: Journal of Business Venturing, 6: 405-429.

Douma, M. / Bilderbeek, J. / Idenbur, P., / Looise, J. (2000) : Strategic alliances: Managing the dynamics of fit. In: Long Range Planning, 33: 579-598.

Doz, Y. L. (1996) : The evolution of cooperation in strategic alliances: Initial conditions or learning processes? In: Strategic Management Journal, $17: 55-83$.

Doz, Y. L. / Hamel, G. (1998) : Alliance advantage: The art of creating value through partnering. Boston: Harvard Business School Press.

Dussauge, P. / Garrette, B. (1999) : Cooperative strategy - Competing successfully through strategic alliances. New York: John Wiley \& Sons, Ltd.

D'Aveni, R. A. (1998) : Waking up to the new era of hypercompetition. In: The Washington Quarterly, 21 (1): 183-195.

Dyer, J. H. / Singh, H. (1998) : The relational view: Cooperative strategy and sources of interorganizational competitive advantage. In: Academy of Management Review, 23 (4): 660-679.

Eisenhardt, K.M. (1985). Control: Organizational and economic approaches. In: Management Science, 31 (2): 134-149.

Eisenhardt, K. M. (1989) : Building theories from case study research. In: Academy of management Review, 14 (4): 532-550.

Eisenhardt, K. M. / Schoonhoven, C. B. (1996) : Resource-based view of strategic alliance formation: Strategic and social effects in entrepreneurial firms. In: Organization Science, 7 (2): 136-150.

Elmuti, D. / Kathawala, Y. (2001) : An overview of strategic alliances. In: Management Decision, 39 (3): 205-218.

Farkas-Conn, I. (1999) : New strategic partnerships between large international banks and small- and medium- sized enterprises. In: Bulletin of the American Society for Information Science, 25 (5): 7-10.

Fielden, S. L. / Davidson, M. J. / Makin, P. J. (2000) : Barriers encountered during.

micro and small business start-up in North West England. In: Journal of Small Business and Enterprise Development, 7 (4) : 295-304.

Galunic, D. C. /Eisenhardt, K. M. (1994) : Reviewing the strategy-structure-performance.

paradigm. In: Research in Organizational Behavior, 16: 215-255.

Gioia, D. A. / Pitre, E. (2001) : Multiparadigm perspectives on theory building. In: Academy of Management Review, 15 (4): 584-602.

Grandori, A. (1997) : An organizational assessment of interfirm coordination modes. In: Organization Studies, 18 (6): 897-925.

Gulati, R. (1995) : Does familiarity breed trust? The implications of repeated ties for contractual choice in alliances. In: Academy of Management Journal, 38 (1): 85-112.

Hagedoorn, J. / Narula, R. (1996) : Choosing organisational modes for strategic technology partnering: International and sectoral differences. In: Journal of International Business Studies, 27 (2): 265-284.

Hall, D. / Hall, I. (1996) : Practical social research: Project work in the community. Basingstoke: MacMillan Press.

Hamel, G. (1991) : Competition for competence and interpartner learning within international strategic alliances. In: Strategic Management Journal, (12): 83-103. 
Howarth, C. / Gillin, M. / Bailey. J. (1995) : Strategic alliances: Resource-sharing strategies for smart companies. Melbourne: Pitman Publishing.

Hutt, M. D. / Stafford, E. R. / Walker, B. A. / Reingen, P. H. (2000) : Defining the social network of a strategic alliance. In: Sloan Management Review, 41 (2): 51-62.

Inkpen, A. C. / Ross, J. (2001) : Why do some strategic alliances persist beyond their useful life? In: California Management Review, 44 (1): 132-148.

Johnston, W. J. / Leach, M. P. / Liu, A. H. (1999) : Theory testing using case studies in business-tobusiness research. In: Industrial Marketing Management, 28 (3): 201-213.

Jones, O. / Tilley, F. (2003) : Competitive advantage in SMEs: Organising for innovation and entrepreneurship. Chichester: Wiley.

Kanter, R. M. (1994) : Collaborative advantage: The art of alliances. Harvard Business Review; 72 (4): 96-108.

Kogut, B. (1998): Joint ventures: Theoretical and empirical perspectives. In: Strategic.

Management Journal, 9 (4): 319-332.

Koza, M. P. / Lewin, A. Y. (1998) : The co-evolution of strategic alliances. In: Organization Science, 9 (3): 255-264.

Kumar, S. / Seth, A. (1998) : The design of coordination and control mechanisms for managing joint venture-parent relationships. In: Strategic Management Journal, 19: 579-599.

Leifer, R. / Mills, P.K. (1996) : An information processing approach for deciding upon control strategies and reducing control loss in emerging organizations. In: Journal of Management, 22: 113-137.

Lewicki, R. J. / Mcallister, D. J. / Bies, R. J. (1998) : Trust and distrust: New relationships and realities. In: Academy of Management Review, 23 (3): 438-458.

Lorange, P. / Roos, J. / Bronn, P. S. (1992) : Building successful strategic alliances. In: Long Range Planning, 25 (6): 10-17.

Mayer, R. C. / Davis, J. H. / Schoorman, F. D. (1995) : An integrative model of organizational trust. In: Academy of Management Review, 20 (3): 709-734.

McGregor, J. / Gomes, C. (1999) : Technology uptake in small and medium-sized enterprises: Some evidence from New Zealand. In: Journal of Small Business Management, 37 (3): 94-102.

Merriam, S. (1988) : Case study research in education: A qualitative approach. San Francisco: Jossey-Bass.

Ministry of Economic Development (2005) : SMEs in New Zealand: Structure and Dynamics. Retrieved Friday, $7^{\text {th }}$ October2005 from http://www.med.govt.nz/irdev/ind_dev/smes/2005/2005.html.

Moor, K. R. (1998) : Trust and relationship commitment in logistics alliances: A buyer perspective. In: The Journal of Supply Chain Management, 34 (1): 24-37.

Ohmae, K. (1989) : The global logic of strategic alliances. In: Harvard Business Review, 67 (2): 143-155.

Perren, L. (1999) : Factors in the growth of micro-enterprises (part 1) : Developing a framework. In: Journal of Small Business and Enterprise Development, 6 (4): 366-385.

Reve, T. (1990) : The firm as a nexus of internal and external contracts. In: Aoki, M./ Gustafsson, B./ Williamson, O.E. (eds.): The firms as a nexus of treaties. London: Sage: 133-161.

Ring, P. S. / Van de Ven, A. (1992) : Structuring cooperative relationships between organizations. In: Strategic Management Journal, 13: 483-498.

Ring, P. S. / Van de Ven, A. (1994) : Developmental processes of cooperative inter-organizational relationships. In: Academy of Management Review, 19 (1): 90-118.

Seligman, M. (2001) : Rules of engagement: How to manage a successful partnership. In: New Zealand Management, 48 (7): 34-38.

Slowinski, G. / Seelig, G. (1996) : Managing technology-based strategic alliances between large and small firms. In: SAM Advanced Management Journal, 61 (2): 42-48.

Spekman, R. E. / Isabella, L. A. / MacAvoy, T. (2000) : Alliance competence. New York: John Whiley \& Sons, Inc.

Sulej, J. C. / Stewart, V. / Keogh, W. (2001) : Taking risk in joint ventures: whose throw of the dice? In: Strategic Change, 10 (5): 285-295.

Volberda, H. W. / Elfring, T. (2001) : Rethinking strategy. London: SAGE Publications.

Williamson, O. E. (1991). Strategising, economising, and economic organisation. In: Strategic Management Journal, 12: 75-94.

Whipple, J. M. / Frankel, R. (2000) : Strategic alliance success factors. In: Journal of Supply Chain Management, 36 (3): 21-28.

Yin, R. (1994) : Case study research: Design and methods. (2d Ed.). Newbury Park: Sage Publications. 